\title{
Knowledge and attitudes of pharmacy students about COVID-19
}

\author{
Emre KARA ${ }^{1 *}$ (D), Nesligül ÖZDEMİR ${ }^{2}$ (D) Gülçin Telli-DİZMAN ${ }^{2}\left(\mathbb{D}\right.$, Kutay DEMİRKAN $^{1}$ (D), \\ Serhat ÜNAL ${ }^{2}$ (D)
}

1 Department of Clinical Pharmacy, Faculty of Pharmacy, Hacettepe University, Sihhiye 06100 Ankara, Turkey.

2 Department of Infectious Diseases and Clinical Microbiology, Faculty of Medicine, Hacettepe University, Sihhiye 06100 Ankara, Turkey.

* Corresponding Author. E-mail: emrekara@hacettepe.edu.tr (E.K.); Tel. +90-312-305 2043.

Received: 15 February 2021 / Revised: 22 June 2021/ Accepted: 28 June 2021

\begin{abstract}
The level of knowledge about COVID-19 varies among students in the field of healthcare. In this study, it was aimed to compare pharmacy students' level of knowledge about COVID-19 before and after an educational seminar. This study was conducted in the first wave of COVID-19 and just at the beginning of the pandemic. A seminar on COVID-19 and protection ways was presented by an infectious disease physician to the pharmacy students in a faculty of pharmacy from Ankara. Before and after the seminar, a questionnaire about COVID-19 consisting of 17 multiple-choice or open-ended questions was applied to the students. A total of 114 pharmacy students (46.5\% female) attended the seminar and all of them participated in the study. The most common information resources in terms of COVID-19 that were used by the participants was internet (non-scientific resources) (n=90, 78.9\%), classical media (TV, newspaper) $(n=79,69.3 \%)$ and social media $(n=77,67.5 \%)$. The rates of knowing that the coronavirus is a zoonotic virus $(p<0.001)$ and awareness of cough and dyspnea, which are symptoms of COVID-19, showed a statistically significant increase after the seminar ( $\mathrm{p}=0.039$ and $\mathrm{p}<0.001$, respectively). The students' knowledge of protection from the disease such as covering the nose and mouth with tissue paper, using eyeglasses, and wearing protective clothing was significantly improved after the seminar $(\mathrm{p}=0.043, \mathrm{p}<0.001, \mathrm{p}<0.004$, respectively). Although the knowledge of pharmacy students about the new pandemic was not insufficient, it had also increased significantly after the seminar. It is thought that determining and improving their knowledge about the pandemic will contribute to pandemic management.
\end{abstract}

KEYWORDS: COVID-19; pharmacy students; knowledge; attitude; coronavirus.

\section{INTRODUCTION}

A new coronavirus pandemic, COVID-19, occurred in Wuhan, China in December 2019 [1]. The World Health Organization declared COVID-19 as a pandemic. COVID-19 cases and deaths were reported afterward in almost all countries, including Turkey [2].

Since the first occurrence of COVID-19 disease, a vast of information about the disease has been spread throughout the world, especially via mass media. Internet, television, and social media, which contain misinformation as well as correct information, have become the most preferred information source by the community [3]. Since the beginning of the pandemic, "symptoms of the disease, ways of protection from the disease, and vaccines for COVID-19" have been the most searched keywords on the internet [4].

Students of medicine, nursing, and pharmacy may have a higher knowledge level even in a new pandemic compared to the community due to their background in the field of health. However, the level of knowledge about COVID-19 varies among students [5]. In a study involving more than 2000 students, it was determined that the factors affecting students' knowledge, attitudes, and behaviors about the new pandemic were age, gender, and academic year of education [6]. In addition, ways of accessing information and information pollution may contribute to students' preconceptions of COVID-19.

During the current COVID-19 pandemic, due to information pollution, counseling of the community is crucial. As a primary healthcare consultant, community pharmacists are a precious information resource for community in this period when accurate information sources are most needed. In this context, pharmacists have an important responsibility to raise awareness of the community about diseases, prevention methods,

How to cite this article: Kara E, Özdemir N, Telli-Dizman G, Demirkan K, Ünal S. Knowledge and attitudes of pharmacy students about COVID-19. J Res Pharm. 2021; 25(6): 898-904. 
and treatments. Pharmacy students are the healthcare professional candidates to take this responsibility upon their graduation [7]. Determining the areas where students have incomplete or incorrect information about the COVID-19 and the factors affecting them will be useful in establishing the approaches to improve their attitudes and behaviors related to the pandemic. This study aimed to evaluate the knowledge and attitudes of pharmacy students about COVID-19 and to assess the impact of an educational seminar on their knowledge and attitudes.

\section{RESULTS}

There were 155 fourth-year pharmacy students at the time of study. A total of 114 (73.5\%) fourth-year pharmacy students (46.5\% femali) participated in this study (Table 1). Regarding the question on 'What are the names of the two coronaviruses that previously responsible for the significant outbreaks?', SARS-CoV was written by $41(36.0 \%)$, and MERS-CoV was written by 20 (17.6\%) students. Other answers were H1N1 (Swine Flu) $(n=6,5.3 \%)$, H5N1 (Bird Flu) $(n=4,3.5 \%)$, Ebola $(n=1,0.9 \%)$, influenza $(n=1,0.9 \%)$, Spanish flu $(n=1,0.9 \%)$ and plague $(\mathrm{n}=1,0.9 \%)$.

Table 1. Demographics of participants and behavior questions about COVID-19, n (\%).

\begin{tabular}{|c|c|c|}
\hline Gender & $\begin{array}{l}\text { Female } \\
\text { Male }\end{array}$ & $\begin{array}{l}53(46.5) \\
61(53.5)\end{array}$ \\
\hline \multirow{3}{*}{$\begin{array}{l}\text { Information resources in terms of } \\
\text { COVID-19 }\end{array}$} & Internet (non-scientific resources) & 90 (78.9) \\
\hline & Classical media (TV, newspaper) & $79(69.3)$ \\
\hline & Social media & $77(67.5)$ \\
\hline \multirow{2}{*}{\multicolumn{2}{|c|}{$\begin{array}{l}\text { Participants had a fear of being infected with SARS-CoV-2. } \\
\text { Participants stated that there is an effective antiviral drug against the COVID-19 disease. } \\
\text { Behavior questions about COVID-19 (multiple answers can be chosen). }\end{array}$}} & $88(77.2)$ \\
\hline & & $9(7.9)$ \\
\hline \multirow{4}{*}{ Do you use a mask for COVID-19? } & I do not use & $107(93.9)$ \\
\hline & In public transport & $4(3.5)$ \\
\hline & While traveling & $4(3.5)$ \\
\hline & In crowded environments & $2(1.8)$ \\
\hline \multirow{7}{*}{$\begin{array}{l}\text { What behaviors do you implement } \\
\text { to protect against COVID-19? }\end{array}$} & I cancel my meetings and activities with my friends. & $27(23.7)$ \\
\hline & I reduce my public transportation use. & $56(49.1)$ \\
\hline & I go to shopping malls less. & $59(51.8)$ \\
\hline & $\begin{array}{l}\text { I participate less in indoor activities such as theater } \\
\text { and cinema. }\end{array}$ & $39(34.2)$ \\
\hline & I try to stay away from coughing people. & $85(74.6)$ \\
\hline & I try to touch less frequently where people touch. & $95(83.3)$ \\
\hline & I wash my hands more than ever. & $96(84.2)$ \\
\hline
\end{tabular}

The majority of the participants (56\% before the seminar, $53.3 \%$ after the seminar) think that "the COVID-19 pandemic will end within 0.5-2 years". There was no change in the answers to this question after the seminar. As the source of infection, 'not fully known' and 'bats' options were selected $(42.6 \%$ and $39.8 \%$, respectively) before the seminar, however, the 'bats' option was frequently chosen (77.2\%) after the seminar $(p<0.001)$. The majority of the students were stated "the incubation period of 2-14 days" both before and after the seminar $(74.5 \%$ and $99.1 \%)$. The mortality rate was defined as $1.1-5 \%$ in pre- and post-seminar $(67.3 \%$ and $86.6 \%$ ) (Table 2).

After the seminar, a significant increase was detected in the rate of those who stated cough $(91.2 \%$ and $98.2 \%, \mathrm{p}=0.021)$, dyspnea $(75.4 \%$ and $93.0 \%, \mathrm{p}<0.001)$, and kidney failure $(9.6 \%$ and $39.5 \%, \mathrm{p}<0.001)$ as symptoms of COVID-19. In addition, the students' knowledge on protection from the disease such as covering the nose and mouth with tissue paper $(53.5 \%$ and $63.2 \%, \mathrm{p}=0.043)$, using eyeglasses $(24.6 \%$ and $46.5 \%$, $\mathrm{p}<0.001)$, and wearing protective clothing $(28.6 \%$ and $43.0 \%, \mathrm{p}=0.004)$ was significantly improved after the seminar. Misinformation of the students on transmission routes of the COVID-19 such as transmitted with sexual intercourse $(30.7 \%$ and $19.3 \%, \mathrm{p}=0.001)$, by blood $(36.8 \%$ and $20.2 \%, \mathrm{p}<0.001)$, and from mother to baby during childbirth $(28.9 \%$ and $14.9 \%, \mathrm{p}<0.001)$ were decreased after the seminar as well as the misinformation on most affected population such as children $(45.6 \%$ and $27.2 \%, \mathrm{p}<0.001)$ and pregnant women $(36.8 \%$ and $18.4 \%, \mathrm{p}<0.002)$. The rate of students' false belief in protective role of turmeric $(9.6 \%$ and $3.5 \%, \mathrm{p}=0.039)$, echinacea $(8.8 \%$ and $2.6 \%, \mathrm{p}=0.016)$ and vinegar use $(21.1 \%$ and $5.3 \%, \mathrm{p}<0.001)$ or rinsing the nose with saline $(41.1 \%$ and $12.2 \%, \mathrm{p}<0.001)$ were also decreased after the seminar (Table 3$)$. 
Table 2. Knowledge questions about COVID-19 (a single answer can be chosen), n (\%).

\begin{tabular}{lcccc}
\hline \multicolumn{1}{c}{ Questions } & Answers & $\begin{array}{c}\text { Before } \\
\text { education }\end{array}$ & $\begin{array}{c}\text { After } \\
\text { education }\end{array}$ & p-value \\
\hline & It is not known & $\mathbf{n = 1 0 8}$ & $\mathbf{n = 1 1 4}$ & \\
What was the first source & clearly & $46(42.6)$ & $24(21.1)$ & $<0.001$ \\
of the infection? & Bats & $43(39.8)$ & $88(77.2)$ & \\
& Others & $19(17.6)$ & $2(1.7)$ & \\
How long is the & $2-14$ days $^{\mathrm{y}}$ & $\mathbf{n = 1 1 0}$ & $\mathbf{n = 1 1 3}$ & \\
incubation period of the & Others & $82(74.5)$ & $112(99.1)$ & $<0.001$ \\
disease? & 1.1-5\% & $\mathbf{2 8}(25.5)$ & $1(0.9)$ & \\
What is the mortality rate & $\mathbf{n = 1 1 3}$ & $\mathbf{n = 1 1 2}$ & \\
\cline { 2 - 5 } from COVID-19? & Othersc & $76(67.3)$ & $97(86.6)$ & $<0.001$ \\
& & $37(32.7)$ & $15(13.4)$ & \\
\hline
\end{tabular}

aOthers: pangolins, camels, humans.

bOthers: $<2$ days, $15-28$ days, $>28$ days

Cothers: $0-1 \%, 5.1-10 \%, 10.1-25 \%,>25 \%$

Table 3. Attitude questions about COVID-19 (multiple answers can be chosen), $\mathrm{n}(\%)$.

\begin{tabular}{|c|c|c|c|c|}
\hline Questions & Answers & $\begin{array}{c}\text { Before } \\
\text { education }\end{array}$ & $\begin{array}{c}\text { After } \\
\text { education }\end{array}$ & p-value \\
\hline \multirow{6}{*}{$\begin{array}{l}\text { In which way(s) is } \\
\text { COVID-19 transmitted? }\end{array}$} & Kissing & $85(74.6)$ & $82(71.9)$ & 0.467 \\
\hline & Shaking hands & $77(67.5)$ & $86(75.4)$ & 0.083 \\
\hline & With sexual intercourse & $35(30.7)$ & $22(19.3)$ & 0.001 \\
\hline & It is transmitted by airborne & $110(96.5)$ & $112(98.2)$ & 0.317 \\
\hline & It is transmitted by blood & $42(36.8)$ & $23(20.2)$ & $<0.001$ \\
\hline & $\begin{array}{l}\text { From mother to baby during } \\
\text { childbirth }\end{array}$ & $33(28.9)$ & $17(14.9)$ & $<0.001$ \\
\hline \multirow{9}{*}{$\begin{array}{l}\text { What is the symptom(s) } \\
\text { or complication(s) of the } \\
\text { infection? }\end{array}$} & Fever & $112(98.2)$ & $112(98.2)$ & 1.000 \\
\hline & Cough & $104(91.2)$ & $112(98.2)$ & 0.021 \\
\hline & Runny nose & $56(49.1)$ & $30(26.3)$ & $<0.001$ \\
\hline & Dyspnea & $86(75.4)$ & $106(93.0)$ & $<0.001$ \\
\hline & Pneumonia & $34(29.8)$ & $34(29.8)$ & 1.000 \\
\hline & Kidney failure & $11(9.6)$ & $45(39.5)$ & $<0.001$ \\
\hline & Bleeding & $1(0.9)$ & $0(0.0)$ & a \\
\hline & Diarrhea & $25(21.9)$ & $12(10.5)$ & 0.003 \\
\hline & Sudden loss of consciousness & $12(10.5)$ & $4(3.5)$ & 0.011 \\
\hline \multirow{5}{*}{$\begin{array}{l}\text { Who is more affected by } \\
\text { COVID-19? }\end{array}$} & Advanced age & $105(92.1)$ & $109(95.6)$ & 0.388 \\
\hline & $\begin{array}{l}\text { People with comorbidities such as } \\
\text { asthma, diabetes, and heart disease. }\end{array}$ & $100(87.7)$ & $106(93.0)$ & 0.146 \\
\hline & Children & $52(45.6)$ & $31(27.2)$ & $<0.001$ \\
\hline & Young adults & $5(4.4)$ & $1(0.9)$ & 0.125 \\
\hline & Pregnant women & $42(36.8)$ & $21(18.4)$ & $<0.001$ \\
\hline \multirow{9}{*}{$\begin{array}{l}\text { Which should be } \\
\text { administered to protect } \\
\text { from COVID-19? }\end{array}$} & Washing hands with soap & $111(97.4)$ & $114(100.0)$ & a \\
\hline & Using hand disinfectant & $111(97.4)$ & $111(97.4)$ & 1.000 \\
\hline & Avoiding contact with sick people & $108(94.7)$ & $111(97.4)$ & 0.453 \\
\hline & $\begin{array}{l}\text { Covering the nose and mouth with } \\
\text { tissue paper }\end{array}$ & $61(53.5)$ & $72(63.2)$ & 0.043 \\
\hline & Using a surgical mask & $53(46.5)$ & $65(67.0)$ & 0.081 \\
\hline & Using an N95 mask & $77(67.5)$ & $78(68.4)$ & 1.000 \\
\hline & Using medical gloves & $55(48.2)$ & $58(50.9)$ & 0.720 \\
\hline & Using protective eyeglasses & $28(24.6)$ & $53(46.5)$ & $<0.001$ \\
\hline & Wearing protective clothing & $33(28.6)$ & $49(43.0)$ & 0.004 \\
\hline \multirow{7}{*}{$\begin{array}{l}\text { Which can prevent } \\
\text { COVID-19? }\end{array}$} & Rinsing the nose with saline & $47(41.2)$ & $14(12.3)$ & $<0.001$ \\
\hline & Using vinegar & $24(21.1)$ & $6(5.3)$ & $<0.001$ \\
\hline & Eating mulberry molasses & $6(5.3)$ & $2(1.8)$ & 0.219 \\
\hline & Using echinacea & $10(8.8)$ & $3(2.6)$ & 0.016 \\
\hline & Using pomegranate peel & $3(2.6)$ & $1(0.9)$ & 0.500 \\
\hline & Using turmeric & $11(9.6)$ & $4(3.5)$ & 0.039 \\
\hline & Using ginger & $10(8.8)$ & $6(5.3)$ & 0.289 \\
\hline
\end{tabular}


After the seminar, a significant increase in the knowledge of the participants was detected on coronaviruses are zoonotic viruses, mainly causing infection in animals' $(71.4 \%$ and $95.5 \%, \mathrm{p}<0.001)$ and necessary facilities are available to diagnose COVID-19 in our country' $(67.5 \%$ and $83.8 \%$, p $<0.001)$ (Table 4). The number of participants that believe in reducing public transportation use in terms of protection $(49.1 \%)$ (Table 1).

Table 4. True answers of participants to knowledge questions about the COVID-19, $\mathrm{n} / \mathrm{n}$ total (\%).

\begin{tabular}{lccc}
\multicolumn{1}{c}{ Proposal } & $\begin{array}{c}\text { Before } \\
\text { education }\end{array}$ & $\begin{array}{c}\text { After } \\
\text { education }\end{array}$ & p-value \\
\hline $\begin{array}{l}\text { Coronaviruses are zoonotic viruses, mainly } \\
\text { causing infection in animals. }\end{array}$ & $80(70.2)$ & $106(93.0)$ & $<\mathbf{0 . 0 0 1}$ \\
$\begin{array}{l}\text { COVID-19 can be treated with antiretroviral drugs. } \\
\text { Necessary facilities are available to diagnose }\end{array}$ & $77(59.6)$ & $80(80.2)$ & 0.052 \\
$\begin{array}{l}\text { COVID-19 in our country. } \\
\begin{array}{l}\text { There is a possibility of SARS-CoV-2 infection from } \\
\text { packages or products from China. }\end{array}\end{array}$ & $93(81.6)$ & $<\mathbf{0 . 0 0 1}$ \\
\hline
\end{tabular}

\section{DISCUSSION}

To the best of our knowledge, this is the first study, which evaluated pharmacy students' knowledge, attitude, and behavior about COVID-19 and examined the impact of an educational seminar on students' knowledge in the first months of the pandemic in Turkey. The most preferred sources for COVID-19 among students were the internet, social media, and news [5, 8]. Similarly, the internet, media, and social media were determined as the most frequently used resources of information in the current study. Due to the easy access and popularity of media, and social media are commonly used information resources among students as well as the community. Nevertheless, it should be taken into account that these sources may contain information pollution.

The level of knowledge about COVID-19 varies among students in the field of healthcare. In a study by Mustafa et al. conducted in Jordan, medical and dental students had significantly higher knowledge levels than pharmacy and nursing students [9]. In another study conducted by Hamza et al., $>70 \%$ of senior pharmacy students had a sufficient COVID-19 knowledge level [10]. The COVID-19-related knowledge level of pharmacy students in the present study was found similar to the study of Hamza et al. It was detected that a large proportion of students had general knowledge on COVID-19, except for a few issues. Followed by the seminar, correct answer rates were increased in questions about transmission ways, symptoms, vulnerable population, protection ways, and preventive ways many questions.

In COVID-19 patients with symptoms, symptoms begin to appear within 5-14 days after exposure and their severity varies on an individual basis. Although the symptoms vary, cough, fever, dyspnea, headache, and sore throat are the most common symptoms of COVID-19 [11]. In the study conducted by Mustafa et al., health care students' awareness of symptoms was quite high; $90 \%$ of students knew the common symptoms of COVID-19 [9]. No COVID-19 case was identified in our country before this study, however, appropriate knowledge on symptoms (fever, cough, and dyspnea) and incubation period (2-14 days) was determined in most of the students. Therefore, according to the results of these studies and our study, the participants' level of knowledge is most likely associated with their interest in the subject rather than the presence of a positive case in their country or being a healthcare professional or not. Besides, having a health knowledge background makes it easier for students to interpret information scientifically which might also explain the level of the students' knowledge.

As the recorded data for COVID-19 patients increased, it was observed that the mortality rates related to the disease in risk groups varied over time between countries. The case-fatality rate was found to be $2.3 \%$ in a wide-ranging assessment in China in February [12]. The estimated global mortality rate in March was $3.4 \%$ according to the World Health Organization [13]. The average mortality rate is thought to be between 2$5 \%$. In this study, only $11 \%$ and $21.2 \%$ of the students perceived the COVID-19-related mortality rate as very low $(0-1 \%)$ and high or very high $(>5 \%)$, respectively. After the seminar, these percentages decreased by approximately $50 \%$.

Due to the high contagiousness in COVID-19 and the high mortality rate in people with comorbidities, vaccine development studies have become a priority target since the disease first appeared. There was no vaccine against COVID-19 yet at the time of the study, but many vaccine studies were in the process $[14,15]$. 
The existing uncertainties when the pandemic first emerged set the ground for the spread of misinformation or myths in the media or among the public about the ways of transmission of the disease, ways of protection from the disease, who the risky groups are, or the control of the disease [16]. In the study conducted by Khasawneh et al., medical students stated that they did not know whether there was transmission through blood (47.6\%), breast milk $(62.0 \%)$, or placenta/birth canal $(50.2 \%)$, while expressing that disease transmitted through contaminated food (53.3\%), or fecal-oral route $(61.4 \%)$. Also, it was found that the students thought that pregnant women $(48.3 \%)$ and children $(23.6 \%)$ were at an increased risk in terms of the disease [17]. In the present study, $30 \%$ to $45 \%$ of the students had misinformation related to the new pandemic on transmission route, risk groups, and prevention methods. Although students do research and interpret the information more scientifically, the unscientific self-opinions of some health professionals shared on social media can mislead people. Unconfirmed and false information about transmission routes (sexual intercourse, from mother to baby during childbirth) and the vulnerable population (child and pregnant) were significantly decreased after the seminar in this study.

According to available data, close contacts, droplets, and aerosol were defined as transmission routes of COVID-19 [18]. Therefore, precautions are also important in terms of protection from the infection. Hand washing, avoiding close contact, and covering the mouth and nose with a mask are determined as the basic principles to be followed to protect against COVID-19 [19]. It was determined that the ratio of knowing the above-mentioned rules that should be followed to prevent the disease among the health care students is above $80 \%$ in the conducted studies $[8,9,17,20]$. Social distance and hand-washing rules were known by almost all students. $[8,20]$ In this study, hand washing, using disinfectants, and avoiding contact with sick individuals were considered by almost all students as a method of protection from disease. Although the rates significantly increased after the training; the awareness of the students about the use of surgical masks and closing the nose and mouth were low compared to other studies in the literature. The seriousness of the situation was not realized by the students could be the explanation of the lower ratios in their belief in the protective role of the mask. Besides, a significant increase was observed in the belief on protective eyeglasses and clothing use after the training.

Studies are showing that herbs such as ginger, curcumin, echinacea, galangal, and some polyphenols (gallic acid, quercetin) have antiviral activities, which are among the subjects that are being researched as a way to prevent or cure COVID-19. However, there is not enough clinical data yet to show that they are effective when used in COVID-19 patients [21, 22]. In the study of Alzoubi et al., drinking ginger with honey $(51 \%)$ and eating garlic (42.7\%) were stated as ways for the prevention of COVID-19 by the students [8]. In this study, $2.6 \%$ to $9.6 \%$ of the students believed that the use of ginger, turmeric, echinacea, pomegranate peel, and mulberry molasses was protective against the disease. There was a significant decrease in the number of students who chose echinacea and ginger for prevention after the seminar. In addition, rinsing the nose with saline and using vinegar was the most preferred option for protection from the disease, but after the seminar percent of the students who selected these choices significantly decreased. All those misleading information is due to influence of the media: on television programs some physicians or some leading people shared those kinds of information, such as rinsing the nose with saline or consumption of some foods or products (such as vinegar, echinacea, mulberry molasses).

Currently, the pathogenesis, transmission dynamics, and infection control measures of COVID-19 are still being learned. Therefore, different practices can be made in the light of current information. It is important to follow the process dynamically and training should be repeated periodically for health care students. Directing to correct sources of information is also important. In terms of infection control measures, to observe positive changes in students' behavior and attitudes, it can be considered to provide information about pandemic regularly using distance education programs.

This study has some limitations. Due to this study was conducted with fourth-year students of a pharmacy school, the participation of the study was limited. The absence of a control group and the evaluation of students right after the seminar are limitations for the study. To present the permanent contribution of the seminar on behaviors, reassessment after a longer duration would be beneficial. Another limitation of the study is that standardized and adequate methods such as interviews and multidimensional measurements were not used to evaluate attitudes and beliefs of the participants. After the education, no significant change was found in responses of the participants with higher level of knowledge before the education. 


\section{CONCLUSION}

Pharmacy students are the candidates for primary healthcare consultant. Therefore, their knowledge and attitudes are important for patient counseling and being a role model. The educational seminar has a positive impact not only on the knowledge of the students but also on their attitudes as well regarding COVID19. It was determined that the basic knowledge of the pharmacy students about COVID-19 was already high before the training, but the wrongly known subjects showed a significant improvement after the seminar.

Internet, classical media and social media have an important role in terms of information resources. Therefore, due to the information pollution of these resources that might have a negative influence on the community, accurate sources should be addressed. Pharmacy educators can play an important role in combating information pollution to direct students to reliable scientific resources instead of social media.

\section{MATERIALS AND METHODS}

In this quasi-experimental study without a control group, pre- and post-evaluation was made before and after an educational seminar regarding to COVID-19. The fourth-year pharmacy students (aged $>18$ years) that voluntarily signed the written consent form were asked to fill the questionnaire before and after the seminar. The seminar organized by the Department of Clinical Pharmacy was held face-to-face by an infectious disease physician as part of the pharmaceutical care lecture for fourth-year students. Within the scope of this seminar, information about the source of COVID-19, ways of transmission, symptoms, approaches to treatment, and ways of protection was presented in 1 hour. The study protocol was approved by the local Ethics Committee (GO-20/364).

The questions included in this questionnaire were created to assess the pharmacy students' attitudes on protection from COVID-19. by using the 'Turkish COVID-19 Scientific Committee COVID-19 Guideline' and the COVID-19 information shared on the Ministry of Health website (https://covid19bilgi.saglik.gov.tr/tr/) by 2 pharmacists and 2 infectious disease physicians.

The 2 pages, Turkish, self-structured questionnaire consisted of 17 multiple-choice, and/or open-ended questions that were administered to fourth-year pharmacy students participating in a live seminar held. The data were analyzed anonymously. Besides, to assess them to understand their interest in the issue, them were asked to write the names of the two coronaviruses that previously responsible for the significant outbreaks.

IBM SPSS Statistics for MacOS, version 23.0 (IBM Corp., Armonk, N.Y., USA) was used for data analysis. Percentage, average, and standard deviation, median, and minimum maximum were used for descriptive data, whereas the Chi-square test was used to compare categorical variables. To determine differences in a dichotomous dependent variable, the McNemar test was used. A 95\% confidence interval was applied to examine the change in data and $\mathrm{p}<0.05$ was considered statistically significant for all tests.

Author contributions: Concept- E.K., K.D., S.U.; Design-E.K., K.D., S.U., G.T.D.; Supervision- K.D., S.U.; Data Collection- E.K., G.T.D.; Analysis- E.K., N.O.; Literature Search- E.K., N.O.; Writing- E.K., N.O.; Critical Reviews- E.K., N.O., K.D., S.U, G.T.D.

Conflict of interest statement: The authors declared no conflict of interest.

Ethics committee approval: The study protocol was approved by the local Ethics Committee on 20th August 2020 with the approval number of GO-20/364.

\section{REFERENCES}

[1] Zhu N, Zhang D, Wang W, Li X, Yang B, Song J, Zhau X, Huang B, Shi W, Lu R, Niu P, Zhan F, Ma X, Wang D, Xu W, Wu G, Gao GF, Tan W. A Novel Coronavirus from Patients with Pneumonia in China, 2019. N Engl J Med. 2020; 382(8): 727 -733. [CrossRef]

[2] Organization WH. Coronavirus disease (COVID-2019) situation reports. https://www.who.int/emergencies/diseases/novel-coronavirus-2019/situation-reports (accessed on 31 January 2021).

[3] Cuan-Baltazar JY, Munoz-Perez MJ, Robledo-Vega C, Perez-Zepeda MF, Soto-Vega E. Misinformation of COVID-19 on the Internet: Infodemiology Study. JMIR Public Health Surveill. 2020; 6(2): e18444. [CrossRef]

[4] Rovetta A, Bhagavathula AS. COVID-19-Related Web Search Behaviors and Infodemic Attitudes in Italy: Infodemiological Study. JMIR Public Health Surveill. 2020; 6(2): e19374. [CrossRef] 
[5] Gohel KH, Patel PB, Shah PM, Patel JR, Pandit N, Raut A. Knowledge and perceptions about COVID-19 among the medical and allied health science students in India: An online cross-sectional survey. Clin Epidemiol Glob Health. 2021; 9:104-109. [CrossRef]

[6] Olaimat AN, Aolymat I, Elsahoryi N, Shahbaz HM, Holley RA. Attitudes, Anxiety, and Behavioral Practices Regarding COVID-19 among University Students in Jordan: A Cross-Sectional Study. Am J Trop Med Hyg. 2020; 103(3): 1177-1183. [CrossRef]

[7] Iwanowicz SL, Marciniak MW, Zeolla MM. Obtaining and providing health information in the community pharmacy setting. Am J Pharm Educ. 2006; 70(3): 57. [CrossRef]

[8] Alzoubi H, Alnawaiseh N, Al-Mnayyis A, Abu-Lubad M, Aqel A, Al-Shagahin H. COVID-19-Knowledge, Attitude and Practice among Medical and Non-Medical University Students in Jordan. J Pure Appl Microbio. 2020; 14(1): 1724. [CrossRef]

[9] Mustafa RM, Alrabadi NN, Alshali RZ, Khader YS, Ahmad DM. Knowledge, Attitude, Behavior, and Stress Related to COVID-19 among Undergraduate Health Care Students in Jordan. Eur J Dent. 2020. [CrossRef]

[10] Hamza MS, Badary OA, Elmazar MM. Cross-Sectional Study on Awareness and Knowledge of COVID-19 Among Senior pharmacy Students. J Community Health. 2020. [CrossRef]

[11] Pascarella G, Strumia A, Piliego C, Bruno F, Del Buono R, Costa F, Scarlata S, Agro FE. COVID-19 diagnosis and management: a comprehensive review. J Intern Med. 2020; 288(2): 192-206. [CrossRef]

[12] Epidemiology Working Group for Ncip Epidemic Response CCfDC, Prevention. The epidemiological characteristics of an outbreak of 2019 novel coronavirus diseases (COVID-19) in China. Zhonghua Liu Xing Bing Xue Za Zhi. 2020; 41(2): 145-151. [CrossRef]

[13] WHO Director-General's opening remarks at the media briefing on COVID-19 - 3 March 2020. https://www.who.int/director-general/speeches/detail/who-director-general-s-opening-remarks-at-the-mediabriefing-on-covid-19---3-march-2020 (accessed on 31 January 2021).

[14] Ahmed SF, Quadeer AA, McKay MR. Preliminary Identification of Potential Vaccine Targets for the COVID-19 Coronavirus (SARS-CoV-2) Based on SARS-CoV Immunological Studies. Viruses. 2020; 12(3): 254. [CrossRef]

[15] Li H, Zhou Y, Zhang M, Wang H, Zhao Q, Liu J. Updated Approaches against SARS-CoV-2. Antimicrob Agents Chemother. 2020; 64(6): e00483-20. [CrossRef]

[16] Kebede Y, Birhanu Z, Fufa D, Yitayih Y, Abafita J, Belay A, Jote A, Ambelu A. Myths, beliefs, and perceptions about COVID-19 in Ethiopia: A need to address information gaps and enable combating efforts. PLoS One. 2020; 15(11): e0243024. [CrossRef]

[17] Khasawneh AI, Humeidan AA, Alsulaiman JW, Bloukh S, Ramadan M, Al-Shatanawi TN, Awad HH, Hijazi WY, AlKammash HR, Obeidat N, Saleh T, Kheirallah KA. Medical Students and COVID-19: Knowledge, Attitudes, and Precautionary Measures. A Descriptive Study From Jordan. Front Public Health. 2020; 8:253. [CrossRef]

[18] Adhikari SP, Meng S, Wu YJ, Mao YP, Ye RX, Wang QZ, Sun C, Sylvia S, Rozelle S, Raat H, Zhou H. Epidemiology, causes, clinical manifestation and diagnosis, prevention and control of coronavirus disease (COVID-19) during the early outbreak period: a scoping review. Infect Dis Poverty. 2020; 9(1): 29. [CrossRef]

[19] How to Protect Yourself \& Others. https://www.cdc.gov/coronavirus/2019-ncov/prevent-gettingsick/prevention.html. (accessed on 21 June 2021).

[20] Noreen K, Rubab ZE, Umar M, Rehman R, Baig M, Baig F. Knowledge, attitudes, and practices against the growing threat of COVID-19 among medical students of Pakistan. PLoS One. 2020; 15(12): e0243696. [CrossRef]

[21] Nugraha RV, Ridwansyah H, Ghozali M, Khairani AF, Atik N. Traditional Herbal Medicine Candidates as Complementary Treatments for COVID-19: A Review of Their Mechanisms, Pros and Cons. Evid Based Complement Alternat Med. 2020; 2020: 2560645. [CrossRef]

[22] Huang J, Tao G, Liu J, Cai J, Huang Z, Chen JX. Current Prevention of COVID-19: Natural Products and Herbal Medicine. Front Pharmacol. 2020; 11: 588508. [CrossRef]

This is an open access article which is publicly available on our journal's website under Institutional Repository at http://dspace.marmara.edu.tr. 